\title{
Letter
}

\section{CYP2D6 genotype and tamoxifen response}

\author{
James M Rae, Matthew P Goetz, Daniel F Hayes, James N Ingle, Lang Li, Anna Maria Storniolo, \\ Vered Stearns and David A Flockhart
}

University of Michigan Medical Center, Department of Internal Medicine, Ann Arbor, Michigan, USA

Corresponding author: James M Rae, jimmyrae@umich.edu

Published: 29 July 2005

This article is online at http://breast-cancer-research.com/content/7/5/E6

(C) 2005 BioMed Central Ltd

Breast Cancer Research 2005, 7:E6 (DOI 10.1186/bcr1297)

See related research by Wegman et al., http://breast-cancer-research.com/content/7/3/R284

We read with interest the article by Wegman and coworkers [1] entitled 'Genotype of metabolic enzymes and the benefit of tamoxifen in postmenopausal breast cancer patients'. The authors conducted a retrospective analysis of a tamoxifen adjuvant clinical trial and reported that a small subset of patients with estrogen receptor (ER)-positive breast cancer treated with tamoxifen who carried the CYP2D6*4 variant allele did significantly better than patients with the same variants not treated with tamoxifen.

We believe that these data are actually not in contrast to data presented by us and others, as the authors suggest. Rather, we believe that alternative interpretations of the data may shed a different light on their conclusions. First, it is important to understand the patients included in this study. They began with a subset of patients (226/679 [33\%]) treated in an adjuvant tamoxifen trial designed to compare the effects of tamoxifen (40 mg/day for 2 years) alone or with chemotherapy, and with or without radiation. Of these, only 112 patients received tamoxifen and only 71 were ER positive. Thus, only $10.5 \%$ of patients in the overall trial $(71 / 679)$ were included in this small substudy, meaning that there is great potential for selection bias.

Initially, the authors did not find a difference in outcome by CYP2D6*4 genotype, and therefore they compared the outcomes in patients with at least one CYP2D6*4 allele who received tamoxifen $(n=24)$ versus no tamoxifen $(n=23)$. They found that patients with the CYP2D6*4 genotype did significantly better than patients not treated with tamoxifen and observed a similar trend in women with the SULT1A1*1 homozygous genotype. They concluded that genotyping of these enzymes may be useful in predicting clinical outcomes and that their findings were in contrast to the current hypotheses on the role of metabolic enzymes in tamoxifen activation and inactivation.

We believe the data presented are consistent with our results, which suggest that CYP2D6 poor metabolizers may experience less benefit from tamoxifen treatment [2]. It is expected that ER-positive women treated with tamoxifen will have better outcomes than ER-positive women treated without tamoxifen, even if they have one CYP2D6*4 allele, because this group would not completely eliminate the benefits of tamoxifen. Indeed, it appears that the data presented by Wegman and coworkers are consistent with this hypothesis, albeit the numbers are very small because of the considerable subsetting and selection.

Our studies have shown that the serum concentration of an active metabolite of tamoxifen, namely endoxifen, is effected by CYP2D6 status in a gene dose dependent manner, with low, intermediate and high concentrations in homozygous variant, heterozygous and homozygous wild-type patients, respectively $[3,4]$. Furthermore, data from a large randomized trial of postmenopausal women receiving adjuvant tamoxifen for 5 years [2] indicate that women who are homozygous (but not heterozygous) for the CYP2D6*4 allele have significantly worse relapse-free survival and disease-free survivals than do women who are heterozygous or homozygous for the common allele. These findings suggest that the outcome of women with 'intermediate' concentrations of endoxifen, as represented by the heterozygous CYP2D6*4, are no different than women who carry two wild-type CYP2D6 alleles. This suggests that the clinical effect of tamoxifen is due to multiple metabolites, and only when women carry two null CYP2D6 alleles, corresponding to the CYP2D6 poor metabolizer phenotype, do outcomes deteriorate.

\section{Competing interests}

The authors(s) declare that they have no competing interests.

\section{References}

1. Wegman P, Vainikka L, Stal O, Nordenskjold B, Skoog L, Rutqvist LE, Wingreb S: Genotype of metabolic enzymes and the benefit of tamoxifen in postmenopausal breast cancer patients. Breast Cancer Res 2005, 7:R284-R290.

2. Goetz MP, Rae JM, Suman VJ, Safgren SL, Ames MM, Vissche DW, Flockhart DA, Adjei AA, Weinshilboum RM, Couch FJ, et al.: Pharmacogenomic determinants of outcome with tamoxifen therapy: findings from the randomized North Central Cancer Treatment Group adjuvant breast cancer trial 89-30-52. Breast Cancer Res Treat 2004, 88:S35.

3. Stearns V, Johnson MD, Rae JM, Morocho A, Novielli A, Bhargava P, Hayes DF, Desta Z, Flockhart DA: Active tamoxifen metabolite plasma concentrations after coadministration of tamoxifen and the selective serotonin reuptake inhibitor paroxetine. $J$ Natl Cancer Inst 2003, 95:1758-1764.

4. Jin $Y$, Desta Z, Stearns V, Ward B, Ho H, Lee KH, Skaar T, Storniolo AM, Li L, Araba A, et al.: CYP2D6 genotype, antidepressant use, and tamoxifen metabolism during adjuvant breast cancer treatment. J Nat/ Cancer Inst 2005, 97:30-39. 